\title{
Diagnostic Challenge
}

\section{Portal venous gas in a patient with abdominal pain}

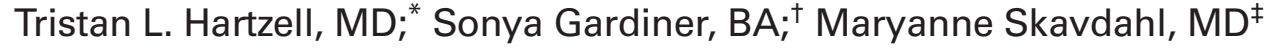

\section{CASE PRESENTATION}

A 77-year-old man with a history of coronary artery disease and paroxysmal atrial fibrillation presented to our emergency department with anorexia, abdominal pain and distension. His abdominal pain had migrated from the periumbilical region to the right lower quadrant. He was passing flatus and had a small, nonbloody bowel movement the day before presentation. He denied any fever. He had undergone no endoscopic procedures within the past year.

On arrival, his temperature was $36.8^{\circ} \mathrm{C}$, blood pressure was $183 / 89 \mathrm{~mm} \mathrm{Hg}$ and pulse rate was 97 beats/ min. His cardiac rhythm was regular. The patient's abdomen was moderately distended and tympanitic, and his right lower quadrant was tender to palpation with rebound tenderness. He was guaiac negative on rectal examination.

Laboratory values were significant for a white blood cell count of $20.3 \times 10^{9} / \mathrm{L}$, a hemoglobin level of $135 \mathrm{~g} / \mathrm{L}$, a hematocrit level of 0.39 proportion of 1.0 and a platelet count of $193 \times 10^{9} / \mathrm{L}$. Results of electrolyte panel and liver function tests were unremarkable. The patient's lactate level was $1.7 \mathrm{mmol} / \mathrm{L}$ and his international normalized ratio was 1.4. An electrocardiogram demonstrated normal sinus rhythm.

Abdominopelvic CT was performed without intravenous contrast and with limited oral contrast. This demonstrated portal venous gas, with large amounts of air within the venous system of the liver (Fig. 1A). There was no evidence of portal vein thrombosis or free air. There were multiple loops of dilated small
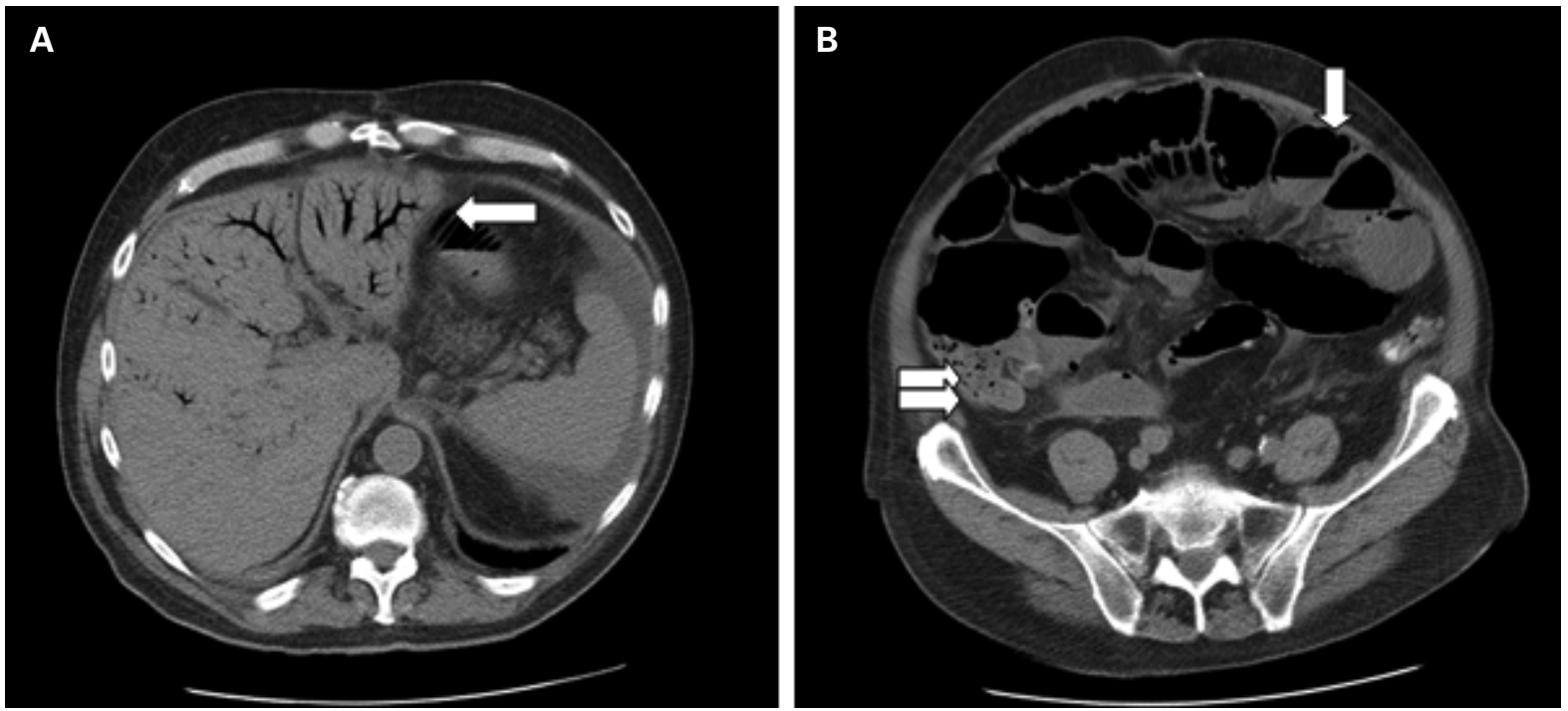

Fig. 1. (A) Abdominal CT scan of a 77-year-old man showing extensive branching air (arrow) within the venous system of the liver. (B) CT scan showing moderately dilated loops of small bowel (arrow). The appendix was not clearly visualized at the base of the cecum (double arrows).

From the *Department of Surgery, Brigham and Women's Hospital, Harvard Medical School, Boston, Mass., the †School of Clinical Medicine, University of Cambridge, Cambridge, UK, and the ¥Department of Medicine, Massachusetts General Hospital, Harvard Medical School, Boston, Mass.

Submitted Dec. 18, 2009; Accepted Jan. 8, 2010

This article has been peer reviewed. 
bowel with no bowel wall thickening (Fig. 1B). The appendix was not clearly visualized at the base of the cecum (Fig. 1B).

\section{QUESTION}

What is the most likely diagnosis?
a) early ischemia of the small bowel
b) perforated gastric ulcer
c) diverticulitis
d) appendicitis
e) inflammatory bowel disease

For the answer to this challenge see page 538.

\section{The Penelope Gray-Allan Memorial CJEM Writing Award: call for papers}

The Canadian Association of Emergency Physicians and the editorial board of CJEM are pleased to announce a call for papers for the first annual award in honour of CJEM's late managing editor, Penelope Gray-Allan. The writing award is open to any FRCPC or CFPC emergency medicine resident in Canada.

The prize will be awarded for a Humour and Humanity article submitted to CJEM by a resident. The paper should be no more than 1000 words. All of the submissions will be judged by either the CJEM Senior Editorial Board, or a committee established by the Senior Editorial Board.

The winning paper will be published in the CAEP Annual Conference edition of CJEM. The author of the winning paper will receive airfare to the CAEP conference, conference admission and 3 nights of hotel accommodations.

The author of the winning paper will receive a plaque acknowledging him/her as the recipient of the annual Penelope Gray-Allan Memorial CJEM Writing Award at the awards ceremony of the CAEP Annual Conference. The first award will be presented at CAEP2011.

Papers may be submitted at http://mc.manuscriptcentral.com/cjem. Submissions are due by Jan. 1, 2011. Please address any questions to cjem@rogers.com. 